\title{
Maximum voltage sag compensation using direct converter by modulating the carrier signal
}

\author{
S. Abdul Rahman, Gebrie Teshome \\ Department of Electrical and Computer Engineering, Institute of Technology, University of Gondar, Ethiopia
}

\begin{tabular}{l}
\hline \hline Article Info \\
\hline Article history: \\
Received Oct 24, 2019 \\
Revised Feb 21, 2020 \\
Accepted Mar 1, 2020 \\
\hline Keywords: \\
Direct converter \\
DVR \\
Modulated carrier signal \\
Series transformer \\
Voltage sag
\end{tabular}

\begin{abstract}
The aim of this paper is to achieve maximum voltage sag compensation of $52 \%$ using direct converter based DVR. The DVR topology has only two switches. The DVR is designed to compensate the voltage sag in a phase by taking power from the same phase. A direct converter is connected between the series transformer and the line in which sag compensation is to be achieved. If the actual amplitude of the error signal is used and the amplitude of carrier signal is kept at 1 unit, it is possible to achieve only $22 \%$ of sag compensation. If the amplitude of the carrier signal is modulated according to the percentage of existing sag, $52 \%$ of the sag is compensated through ordinary PWM technique with the THD less than 5\%. Matlab Simulation results are presented for the validating the analysis.
\end{abstract}

Copyright () 2020 Institute of Advanced Engineering and Science. All rights reserved.

Corresponding Author:

S. Abdul Rahman,

Department of Electrical and Computer Engineering, Institute of Technology,

University of Gondar, Gondar, Ethiopia.

Email: msajce.abdulrahman@gmail.com

\section{INTRODUCTION}

Though we have many power quality issues like sag, swell, flicker, harmonics, voltage sag is considered to be the severe issue as it affects the operation of sensitive loads like computer, micro controller, Digital Signal Processor, FPGA. As most of the industries are automated, the entire operation of the industries depends upon the operating condition of these sensitive loads. When sag or swell occurs in the industrial areas, these sensitive loads are getting affected, leading to immoral operation of the entire industry [1-8]. For the compensation of voltage sag, Dynamic Voltage Restorer (DVR) considered to be an effective device when compared to other devices like UPS, STATCOM [9-11]. Though many DVR topologies like DVR based on energy storage devices (like batteries, capacitors and super capacitors) have been proposed [12-17], in this paper DVR based on direct convert is presented [18-22]. The compensating range of the DVRs based on energy storage devices, depends upon the rating of the energy storage devices, but in the DVRs based on direct converters, it is based on the availability of voltage in the phase from which the power is taken for compensation and modulating techniques. In the DVR topologies based on direct converter, so far a maximum sag compensation of $33 \%$ had been done [23]. Even from the analysis done in this paper (direct converter based DVR, in which, to mitigate voltage sag in one phase the power will be taken from the same phase) by ordinary PWM technique, it is possible to achieve only $22 \%$ of sag compensation. If the carrier signal is modulated according to the percentage of existing sag, it is been shown in this paper that it is possible to achieve $52 \%$ of sag compensation.

\section{PRINCIPLE OF OPERATION}

The topology of the direct converter based DVR is been shown in the Figure 1. It has a direct converter, a LC filters at the input side of the direct converter and another LC filter at the output side of 
the converter, and a series transformer. The LC filters are to minimize the harmonics due to switching. The direct converter has two bidirectional switches S1 and S2 as shown in the Figure 1. The topology of the bidirectional switch is shown in the Figure 2.

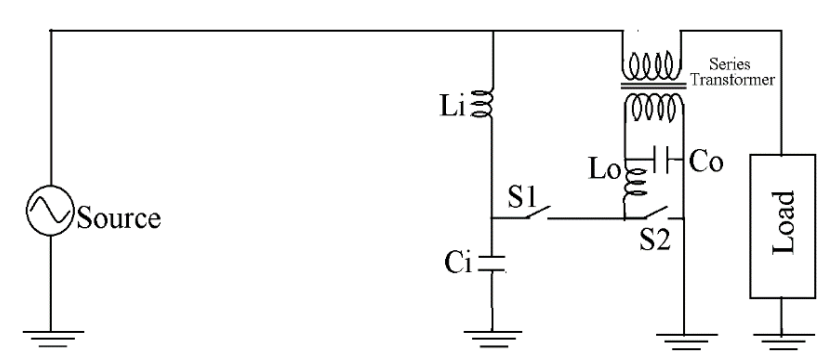

Figure 1. Topology of the DVR

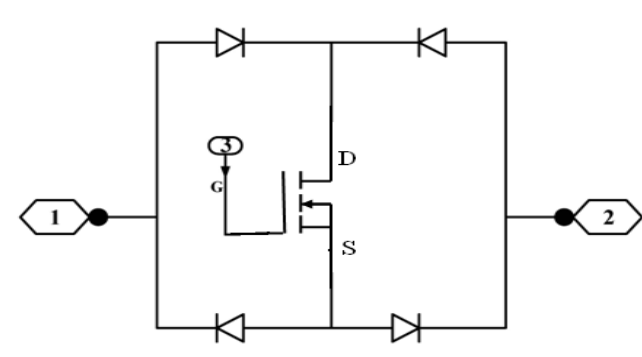

Figure 2. Topology of the bidirectional switch

When the supply voltage is at rated value, the switch $\mathrm{S} 1$ is open and switch $\mathrm{S} 2$ is closed. In this condition, the secondary of the series transformer is short circuited which results in zero voltage injection and the load voltage is maintained at its rated value. When the sag occurs, the DVR will synthesis the compensating voltage by taking power from the same phase and operating the switches S1 and S2 alternatively. The compensating voltage is added in phase with the supply voltage through the series transformer. The turns ratio of the series transformer is $1: 1$.

\section{CONTROL ALGORITHM}

The supply side voltage is measured and the peal value of the instantaneous voltage is calculated using single phase dq theory [24-26]. It is compared with the peak value of the rated voltage to generate the error signal. The error signal is compared with the carrier to generate PWM for controlling the switches as shown in the Figure 3.

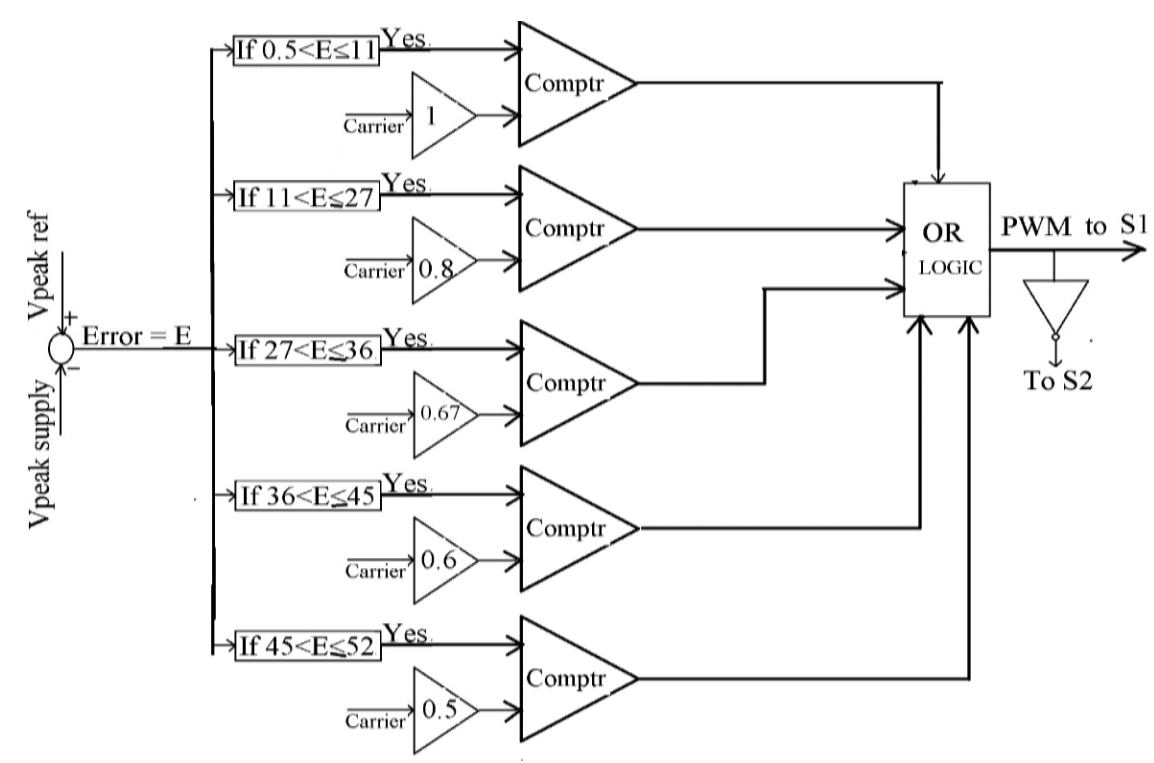

Figure 3. Block diagram for PWM generation with modulated error signal

In order to generate the PWM, the amplitude of the carrier is signal is kept at 1 unit. The actual error signal in per unit is compared with the carrier signal. It is been observed from the table 1that if the actual error signal is used to generate PWM, it is possible to achieve only $22 \%$ of sag compensation. Though there is a compensation by the DVR for more than $22 \%$ of sag, the load voltage is not met with the IEEE standard. But it is possible to improve the range of sag compensation, since sufficient voltage is available at the supply 
side to mitigate sag up to $52 \%$. It could be observed from the Table 1 that, for a sag of $22 \%$, the duty cycle of the PWM is only $22 \%$. So by increasing the duty cycle of the PWM the compensating range also could be increased. The duty cycle could be increased by modulating the carrier signal amplitude according to the percentage of sag. The carrier signal is modulated in such a way that, if the sag is 0 to $11 \%$, the carrier is not modulated and the actual error is compared with the carrier to generate the PWM to control the switches. For a sag of more than $11 \%$ and less than or equal to $27 \%$, the error is amplitude of the carrier signal is kept at 0.8 unit. If the sag is more than $27 \%$ and less than or equal to $36 \%$, the carrier is amplitude modulated by a gain of 0.67 . For the sag of more than $36 \%$ and less than or equal to $45 \%$, the carrier is amplitude modulated by a gain of 0.6 . For the sag of more than $45 \%$ and less than or equal to $52 \%$, the carrier is modulated by the gain of 0.5 . It could be observed from the Table 2 that the compensated load voltage for the chosen modulation factor is maintained within the IEEE standard value.

Table 1. Possible compensation without modulating the carrier signal

\begin{tabular}{cccccc}
\hline $\begin{array}{c}\text { Supply Voltage } \\
\text { in Volts }\end{array}$ & $\begin{array}{c}\% \text { of } \\
\text { Sag }\end{array}$ & Error & $\begin{array}{c}\text { Duty Cycle } \\
\text { of PWM }\end{array}$ & $\begin{array}{c}\text { Compensating voltage generated by the } \\
\text { DVR = Supply Voltage * Duty Cycle }\end{array}$ & $\begin{array}{c}\text { LoadVoltage }=\text { Supply } \\
\text { Voltage + Duty Cycle }\end{array}$ \\
\hline 100 & $0 \%$ & 0 & 0 & 0 & 100 \\
90 & $10 \%$ & 10 & $10 \%$ & 9 & 99 \\
80 & $20 \%$ & 20 & $20 \%$ & 16 & 96 \\
78 & $22 \%$ & 22 & $22 \%$ & 17.16 & 95.16 \\
77 & $23 \%$ & 23 & $23 \%$ & 17.71 & 94.71 \\
76 & $24 \%$ & 24 & $24 \%$ & 21 & 94.24 \\
70 & $30 \%$ & 30 & $30 \%$ & 24 & 91 \\
60 & $40 \%$ & 40 & $40 \%$ & 25 & 84 \\
50 & $50 \%$ & 50 & $50 \%$ & & 75 \\
\hline
\end{tabular}

Table 2. Possible Compensation by modulating the carrier signal

\begin{tabular}{|c|c|c|c|c|c|c|c|}
\hline \multirow[t]{2}{*}{ Vsupply } & \multirow[t]{2}{*}{ Sag in $\%$} & \multirow[t]{2}{*}{ Error in $\%$} & \multicolumn{5}{|c|}{ Load Voltage for Modulating Factor of } \\
\hline & & & 1 & 0.8 & 0.67 & 0.6 & 0.5 \\
\hline 100 & 0 & 0 & 100.0 & 100.0 & 100.0 & 100.0 & 100.0 \\
\hline 99 & 0.01 & 0.01 & 100.0 & 100.2 & 100.5 & 100.7 & 101.0 \\
\hline 98 & 0.02 & 0.02 & 100.0 & 100.5 & 100.9 & 101.3 & 101.9 \\
\hline 97 & 0.03 & 0.03 & 99.9 & 100.6 & 101.3 & 101.9 & 102.8 \\
\hline 96 & 0.04 & 0.04 & 99.8 & 100.8 & 101.7 & 102.4 & 103.7 \\
\hline 95 & 0.05 & 0.05 & 99.8 & 100.9 & 102.1 & 102.9 & 104.5 \\
\hline 95 & 0.05 & 0.05 & 99.8 & 100.9 & 102.1 & 102.9 & 104.5 \\
\hline 94 & 0.06 & 0.06 & 99.6 & 101.1 & 102.4 & 103.4 & 105.3 \\
\hline 93 & 0.07 & 0.07 & 99.5 & 101.1 & 102.7 & 103.9 & 106.0 \\
\hline 92 & 0.08 & 0.08 & 99.4 & 101.2 & 103.0 & 104.3 & 106.7 \\
\hline 91 & 0.09 & 0.09 & 99.2 & 101.2 & 103.2 & 104.7 & 107.4 \\
\hline 90 & 0.1 & 0.1 & 99.0 & 101.3 & 103.4 & 105.0 & 108.0 \\
\hline 89 & 0.11 & 0.11 & 98.8 & 101.2 & 103.6 & 105.3 & 108.6 \\
\hline 88 & 0.12 & 0.12 & 98.6 & 101.2 & 103.8 & 105.6 & 109.1 \\
\hline 87 & 0.13 & 0.13 & 98.3 & 101.1 & 103.9 & 105.9 & 109.6 \\
\hline 86 & 0.14 & 0.14 & 98.0 & 101.1 & 104.0 & 106.1 & 110.1 \\
\hline 85 & 0.15 & 0.15 & 97.8 & 100.9 & 104.0 & 106.3 & 110.5 \\
\hline 84 & 0.16 & 0.16 & 97.4 & 100.8 & 104.1 & 106.4 & 110.9 \\
\hline 83 & 0.17 & 0.17 & 97.1 & 100.6 & 104.1 & 106.5 & 111.2 \\
\hline 82 & 0.18 & 0.18 & 96.8 & 100.5 & 104.0 & 106.6 & 111.5 \\
\hline 81 & 0.19 & 0.19 & 96.4 & 100.2 & 104.0 & 106.7 & 111.8 \\
\hline 80 & 0.2 & 0.2 & 96.0 & 100.0 & 103.9 & 106.7 & 112.0 \\
\hline 79 & 0.21 & 0.21 & 95.6 & 99.7 & 103.8 & 106.7 & 112.2 \\
\hline 78 & 0.22 & 0.22 & 95.2 & 99.5 & 103.6 & 106.6 & 112.3 \\
\hline 77 & 0.23 & 0.23 & 94.7 & 99.1 & 103.4 & 106.5 & 112.4 \\
\hline 76 & 0.24 & 0.24 & 94.2 & 98.8 & 103.2 & 106.4 & 112.5 \\
\hline 75 & 0.25 & 0.25 & 93.8 & 98.4 & 103.0 & 106.3 & 112.5 \\
\hline 74 & 0.26 & 0.26 & 93.2 & 98.1 & 102.7 & 106.1 & 112.5 \\
\hline 73 & 0.27 & 0.27 & 92.7 & 97.6 & 102.4 & 105.9 & 112.4 \\
\hline 72 & 0.28 & 0.28 & 92.2 & 97.2 & 102.1 & 105.6 & 112.3 \\
\hline 71 & 0.29 & 0.29 & 91.6 & 96.7 & 101.7 & 105.3 & 112.2 \\
\hline 70 & 0.3 & 0.3 & 91.0 & 96.3 & 101.3 & 105.0 & 112.0 \\
\hline 69 & 0.31 & 0.31 & 90.4 & 95.7 & 100.9 & 104.7 & 111.8 \\
\hline 68 & 0.32 & 0.32 & 89.8 & 95.2 & 100.5 & 104.3 & 111.5 \\
\hline 67 & 0.33 & 0.33 & 89.1 & 94.6 & 100.0 & 103.9 & 111.2 \\
\hline 66 & 0.34 & 0.34 & 88.4 & 94.1 & 99.5 & 103.4 & 110.9 \\
\hline 65 & 0.35 & 0.35 & 87.8 & 93.4 & 99.0 & 102.9 & 110.5 \\
\hline 64 & 0.36 & 0.36 & 87.0 & 92.8 & 98.4 & 102.4 & 110.1 \\
\hline 63 & 0.37 & 0.37 & 86.3 & 92.1 & 97.8 & 101.9 & 109.6 \\
\hline
\end{tabular}


Table 2. Possible compensation by modulating the error signal (continue)

\begin{tabular}{lccccccc}
\hline Vsupply & Sag in \% & Error in \% & \multicolumn{5}{c}{ Load Voltage for Modulating Factor of } \\
& & & 1 & 0.8 & 0.67 & 0.6 & 0.5 \\
\hline 62 & 0.38 & 0.38 & 85.6 & 91.5 & 97.2 & 101.3 & 109.1 \\
61 & 0.39 & 0.39 & 84.8 & 90.7 & 96.5 & 100.7 & 108.6 \\
60 & 0.4 & 0.4 & 84.0 & 90.0 & 95.8 & 100.0 & 108.0 \\
59 & 0.41 & 0.41 & 83.2 & 89.2 & 95.1 & 99.3 & 107.4 \\
58 & 0.42 & 0.42 & 82.4 & 88.5 & 94.4 & 98.6 & 106.7 \\
57 & 0.43 & 0.43 & 81.5 & 87.6 & 93.6 & 97.9 & 106.0 \\
56 & 0.44 & 0.44 & 80.6 & 86.8 & 92.8 & 97.1 & 105.3 \\
55 & 0.45 & 0.45 & 79.8 & 85.9 & 91.9 & 96.3 & 104.5 \\
54 & 0.46 & 0.46 & 78.8 & 85.1 & 91.1 & 95.4 & 103.7 \\
53 & 0.47 & 0.47 & 77.9 & 84.1 & 90.2 & 94.5 & 102.8 \\
52 & 0.48 & 0.48 & 77.0 & 83.2 & 89.3 & 93.6 & 101.9 \\
51 & 0.49 & 0.49 & 76.0 & 82.2 & 88.3 & 92.7 & 101.0 \\
50 & 0.5 & 0.5 & 75.0 & 81.3 & 87.3 & 91.7 & 100.0 \\
49 & 0.51 & 0.51 & 74.0 & 80.2 & 86.3 & 90.7 & 99.0 \\
48 & 0.52 & 0.52 & 73.0 & 79.2 & 85.3 & 89.6 & 97.9 \\
\hline
\end{tabular}

\section{SIMULATION RESULTS}

For easy understanding, the rated value of supply voltage is set with the amplitude of $100 \mathrm{~V}, 50 \mathrm{~Hz}$. The DVR operates with the filter inductance of $1 \mathrm{mH}$ and filter capacitance of $15 \mathrm{uF}$ at the carrier frequency of $4 \mathrm{KHz}$. The following Figures 4-8 shows the ability of the control algorithm to mitigate sag from 0 to $52 \%$.

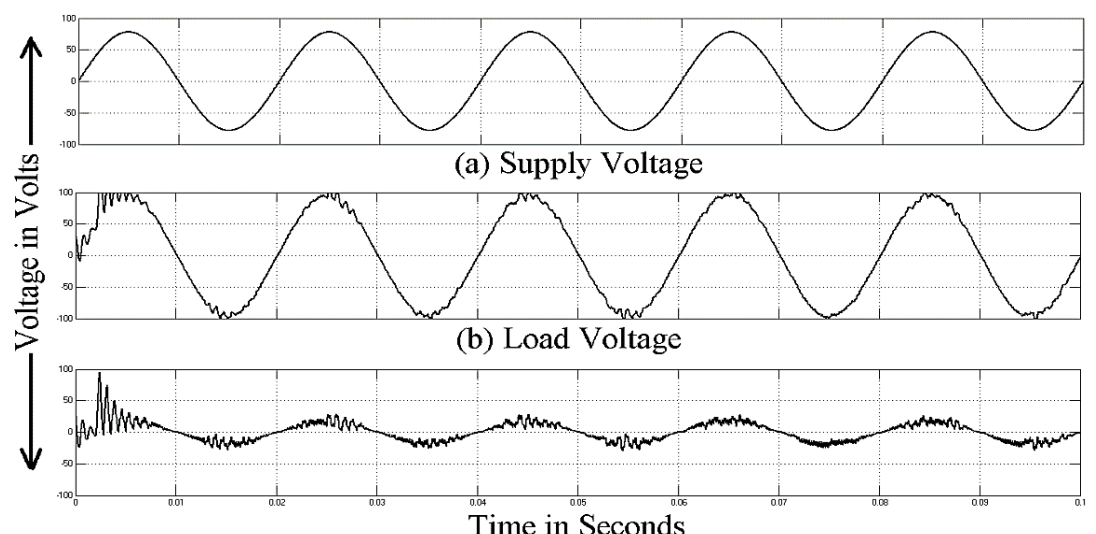

(c) Compensating Voltage produced by the DVR

Figure 4. Sag compensation of $22 \%$

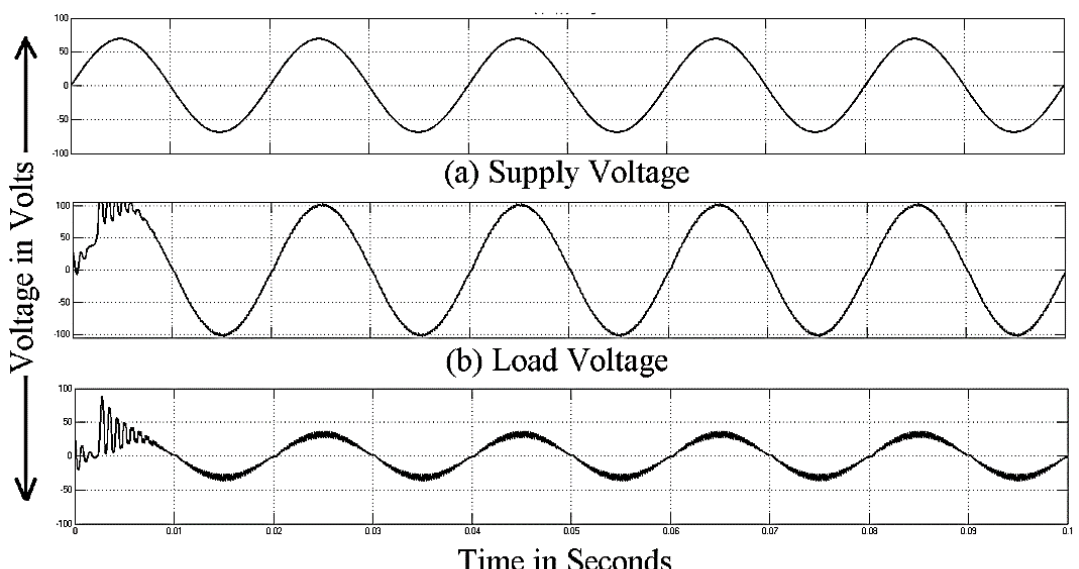

(c) Compensating Voltage produced by the DVR

Figure 5. Sag compensation of $30 \%$ 


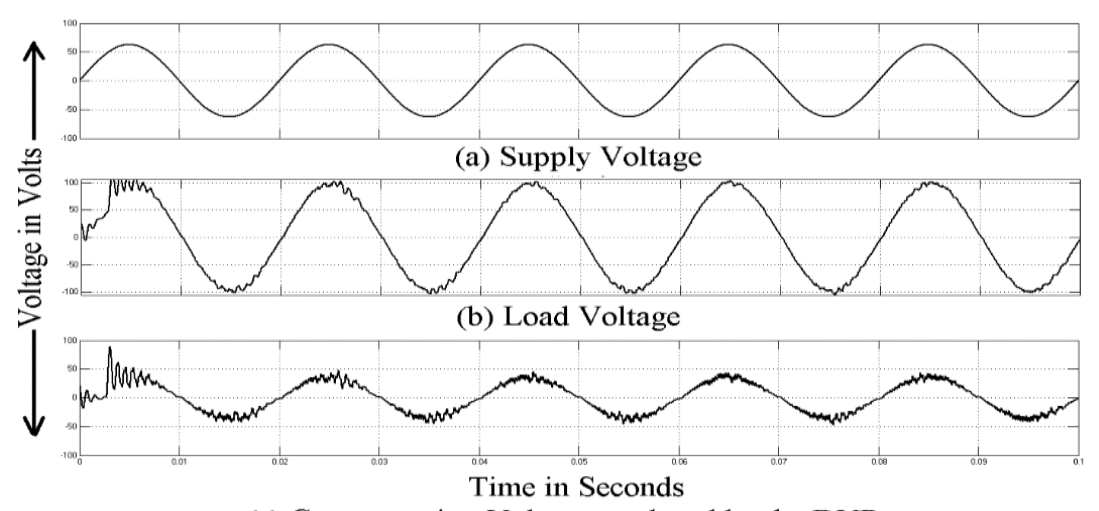

(c) Compensating Voltage produced by the DVR

Figure 6. Sag compensation of $37 \%$

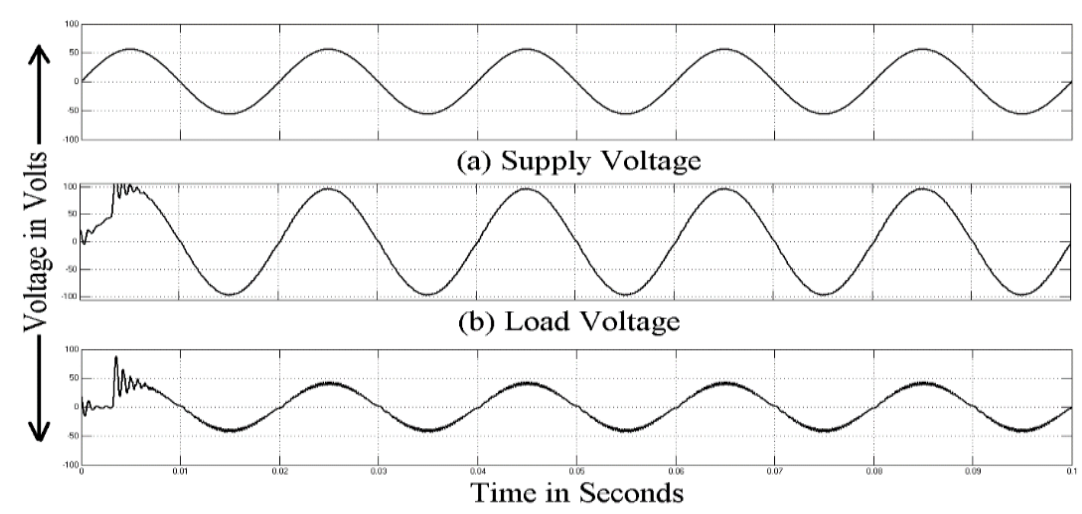

(c) Compensating Voltage produced by the DVR

Figure 7. Sag compensation of $45 \%$

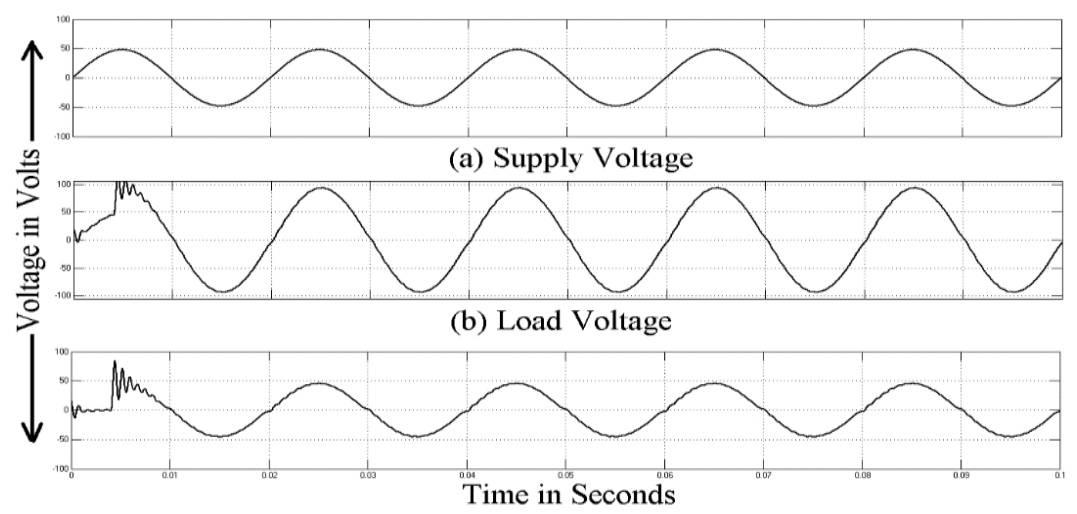

(c) Compensating Voltage produced by the DVR

Figure 8. Sag Compensation of 52\%

\section{CONCLUSION}

As the DVR is constructed using direct converter, energy storage devices are avoided which leads to saving of cost, space, weight and maintenance. During compensation only two switches are alternatively modulated. Thus switching losses are minimized and switching pulse generation is easier. With all these advantages, it is been demonstrated in this paper that it is possible to achieve $52 \%$ of sag compensation by modulating the carrier signal according to the percentage of voltage sag, using a DVR based on direct converter with THD less than 5\%. 


\section{REFERENCES}

[1] S. Suraya, P. Sujatha, and P. B. Kumar, "Contemporary control of DG integrated DVR for sag, swell and harmonic mitigation," International Journal of Electrical and Computer Engineering, vol. 8, no. 5, pp. 2721-2730, 2018.

[2] W. Tee, et al, "Voltage variations identification using gabor transform and rule-based classification method," International Journal of Electrical and Computer Engineering, vol. 10, no 1, pp. 681-689, 2020.

[3] A. Farooqi, et al, "Mitigation of power quality problems using series active filter in a microgrid system," International Journal of Power Electronics and Drive Systems, vol. 10, no. 4, pp. 2245-2253, 2019.

[4] N. S. Srivatchan, and P. Rangarajan, "Half cycle discrete transformation for voltage sag improvement in an islanded microgrid using dynamic voltage restorer," International Journal of Power Electronics and Drive Systems, vol. 9, no. 1, pp. 25-32, 2018

[5] K. K. Deepika, J. V. Kumar, and G. K. Rao, "Enhancement of voltage regulation using a 7-Level inverter based electric spring with reduced number of switches," International Journal of Power Electronics and Drive Systems, vol. 11 , no. $2,2020$.

[6] K. Daud, et al, "Evaluating windowing-based continuous S-transform with neural network classifier for detecting and classifying power quality disturbances," Indonesian Journal of Electrical Engineering and Computer Science, vol. 13, no. 3, pp. 1136-1142, 2019.

[7] A. S. Hussein, and M. N. Hawas, "Power quality analysis based on simulation and MATLAB/Simulink," Indonesian Journal of Electrical Engineering and Computer Science, vol. 16, no. 3, pp. 1144-1153, 2019.

[8] S. Shahbudin, et al, "Fault disturbances classification analysis using adaptive neuro-fuzzy inferences system," Indonesian Journal of Electrical Engineering and Computer Science, vol. 16, no. 3, pp. 1196-1202, 2019.

[9] Amirullah, O. Penangsang, and A. Soeprijanto, "Matlab/simulink simulation of unified power quality conditionerbattery energy storage system supplied by PV-wind hybrid using fuzzy logic controller," International Journal of Electrical and Computer Engineering, vol. 9, no. 3, pp. 1479-1495, 2019.

[10] D. Danalakshmi, S. Bugata, and Kohila J, "A control strategy on power quality improvement in consumer side using custom power device," Indonesian Journal of Electrical Engineering and Computer Science, vol. 15, no. 1, pp. 80-87, 2019.

[11] A. M. Nori, and T. K. Hassan, "Modeling and simulation of quasi-Z-source indirect matrix converter for permanent magnet synchronous motor drive," International Journal of Power Electronics and Drive Systems, vol. 10, no. 2, pp. 882-899, 2019.

[12] J. Wang, et al, "A novel Dual-DC-Port dynamic voltage restorer with reduced-rating integrated DC-DC converter for wide-range voltage sag compensation," IEEE Transactions on Power Electronics, vol. 34, no. 8, pp. 7437-7449, 2019.

[13] P. A. Janakiraman and S. Abdul Rahman, "Linear Pulsewidth Modulation Under Fluctuating Power Supply," in IEEE Transactions on Industrial Electronics, vol. 61, no. 4, pp. 1769-1773, April 2014.

[14] R. Omar, and N. A. Rahim, "Voltage unbalanced compensation using dynamic voltage restorer based on supercapacitor," International Journal of Electrical Power \& Energy Systems, vol. 43, no. 1, pp. 573-581, 2012.

[15] Kheibar, M., et al., "Design of novel approach to mitigate voltage sag caused by starting an induction motor using dynamic voltage restorer," Majlesi Journal of Electrical Engineering, vol. 10, no. 4, pp. 25-31, 2016.

[16] A. B. Mohammed, M. A. M. Ariff, and S. N. Ramli, "Power quality improvement using dynamic voltage restorer in electrical distribution system: an overview," Indonesian Journal of Electrical Engineering and Computer Science, vol. 17, no. 1, pp. 86-93, 2020.

[17] T. Toumi, et al, "PV integrated single-phase dynamic voltage restorer for sag voltage," International Journal of Power Electronics and Drive Systems, voltage fluctuations and harmonics compensation, vol. 11, no. 1, pp. 547-554, 2020.

[18] S. Jothibasu, and M. K. Mishra, "A Control Scheme for Storage less DVR Based on Characterization of Voltage Sags," IEEE Transactions on Power Delivery, vol. 29, no. 5, pp. 2261-2269, 2014.

[19] M. M. Othman, et al., "Energy efficiency enhancement using dynamic voltage restorer (DVR)," International Journal of Power Electronics and Drive Systems, vol. 10, no. 3, pp. 1308-1316, 2019.

[20] D. V. Chinmay, and D. V. Chaitanya, "Optimum design of dynamic voltage restorer for voltage sag mitigation in distribution network," International Journal of Power Electronics and Drive Systems, vol. 10, no. 3, pp. 1364-1372, 2019.

[21] S. Abdul Rahman, P.A. Janakiraman and P. Somasundaram, "Voltage sag and swell mitigation based on modulated Carrier PWM," International Journal of Electrical Power and Energy Systems, Elsevier, Vol. 66, pp. 78-85, 2015.

[22] S. Abdul Rahman and P. Somasundaram, "Voltage sag and swell compensation using AC/AC converters," Australian Journal of Electrical \& Electronics Engineering, Vol. 11, No. 2, pp. 186-194, 2014.

[23] E. Babaei, M. F. Kangarlu, and M. Sabahi, "Mitigation of voltage disturbances using dynamic voltage restorer based on direct converters," IEEE Transactions on Power Delivery, vol. 25, no. 4, pp. 2676-2683, 2010.

[24] S. Abdul rahman, and P. Somasundaram, "Mitigation of Voltage Sag and Swell Using Dynamic Voltage Restorer without Energy Storage Devices," International Review of Electrical Engineering, vol. 7, No.4, pp. 4948-4953, 2012.

[25] Abdul Rahman Syed Abuthahir, Somasundaram Periasamy, Janakiraman Panapakkam Arumugam, "Mitigation of Voltage Sag and Swell Using Direct Converters with Minimum Switch Count," Journal of Power Electronics, Vol. 14, No. 6, pp. 1314-1321, 2014.

[26] S. Abdul Rahman, "Direct converter based DVR to mitigate single phase outage," International Journal of Recent Technology and Engineering (IJRTE), vol. 8, no. 3, pp. 85-88, 2019. 